\title{
Němec, Richard (2020): Die Ökonomisierung des Raums. Planen und Bauen in Mittel- und Osteuropa unter den Nationalsozialisten 1938 bis 1945
}

\author{
Karl R. Kegler \\ Eingegangen: 12. November 2020 - Angenommen: 2. Dezember 2020 - Online veröffentlicht: 23. Januar 2021
}

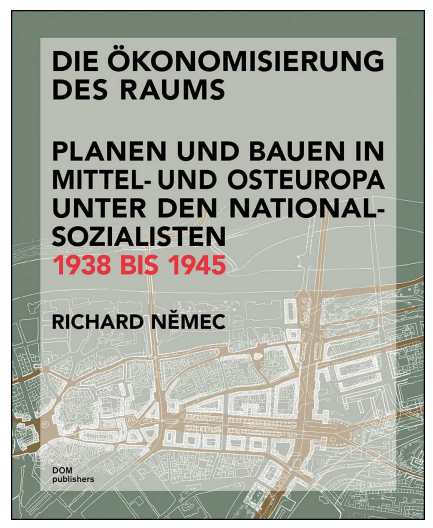

Eine Fülle von zum überwiegenden Teil in der deutschsprachigen Forschung bisher unbekanntem Material bietet der gewichtige Band „Die Ökonomisierung des Raums. Planen und Bauen in Mittel- und Osteuropa unter den Nationalsozialisten 1938 bis 1945“, der im Oktober 2020 als einer von zehn Titeln mit dem „Architectural Book Award“ der Frankfurter Buchmesse und des Deutschen Architekturmuseums ausgezeichnet wurde. Das Buch betrachtet in seinen zentralen Kapiteln Planungen für vier Städte auf dem Gebiet der Tschechoslowakei: Reichenberg (Liberec) als Hauptstadt der als Reichsgau Sudetenland nach dem Münchner Abkommen 1938 an NS-Deutschland angegliederten Gebiete, Prag als Zentrum des 1939 besetzten Protektorates Böhmen und Mähren sowie Pressburg (Bratislava) als neue

$\triangle$ Prof. Dr. Karl R. Kegler, Fakultät für Architektur, Hochschule München, Karlstraße 6, 80333 München

karl.kegler@hm.edu

(c) (1) () ( 2021 Kegler; licensee oekom verlag. This Open Access article is published under the Creative Commons Attribution-ShareAlike 4.0 International Licence.
Kapitale der im gleichen Jahr geschaffenen, autoritär regierten und mit den Achsenmächten verbündeten Slowakischen Republik. Einen Sonderfall stellt Karlsbad (Karlovy Vary) im Reichsgau Sudetenland dar. Neben den drei genannten Hauptstädten widmet Richard Němec dem geplanten Ausbau dieser Stadt zum „Weltkurort“ ein eigenes Kapitel. Ergänzt werden die vier Fallstudien durch Referenzen zu „Ostsiedlung und Städtebau“ aus dem besetzten Polen. Hier präsentiert der Autor Materialien und Pläne für die Städte Warschau, Krakau und Posen.

Der Berner Kunsthistoriker Richard Němec versteht seine Studie als eine architekturgeschichtliche Arbeit (S. 9) und wählt ein komparatistisches Vorgehen (S. 47), das Ansätze aus den Bereichen Stadtplanung, Architekturgeschichte, Denkmalpflege und politische Geschichte kombiniert. Zur Einordnung der Fallbeispiele in den Kontext der nationalsozialistischen Stadt- und Raumplanung spannt die Untersuchung im einleitenden und abschließenden Teil ein doppeltes Bezugssystem auf. Zum einen deutet Němec die Planungen für die (Haupt)Städte auf dem Gebiet der ehemaligen Tschechoslowakei als Ausdruck der NS-Siedlungsund Germanisierungspolitik im Kontext des „Generalplan Ost“. Zum anderen stellt er seine Fallstudien im besetzten Polen und in der Tschechoslowakei in den Kontext der Umgestaltung der reichsdeutschen Führer- und Gauhauptstädte. Das Bindeglied zu diesen Planungen sieht er in der Funktion Albert Speers, der als Generalbauinspektor für die Reichshauptstadt (bis zum 17. Januar 1941) auch für die Neugestaltung wichtiger Städte außerhalb Berlins verantwortlich zeichnete. Als Speer sich Anfang 1941 aus der Verantwortung für diese Planungen im Reich und den besetzten Gebieten zurückzieht, um sich ganz seinen Aufgaben in Berlin und Nürnberg widmen zu können, setzen Prozesse ein, die Němec für seine vier Referenzstädte detail- 
reich nachzeichnet: „Zwar hatten sich diese Planungen zumindest anfänglich an den in Deutschland erarbeiteten Systematiken zu orientieren, sie verselbstständigten sich später jedoch" (S. 446). Für die Gruppe einheimischer deutschsprachiger Planer bedeutet dies allerdings, ,dass sie deutlich und bewusst von der Reichsverwaltung und den Reichsarchitekten verdrängt wurde“" (S. 450).

$\mathrm{Zu}$ den Ergebnissen der Arbeit gehören unter anderem neue Details zur Beteiligung des brandenburgischen Landesplaners und Präsidenten der „Deutschen Akademie für Städtebau und Landesplanung", Reinhold Niemeyer, an den NS-Planungen für die Umgestaltung der tschechischen Hauptstadt in eine „deutsche Stadt“. Němec führt hier zugleich den bisher meist übersehenen Anteil tschechischer Planer vor. Während für den avisierten Umbau Prags das Vorbild Berlin zum Tragen kam (S. 454), zeigt der Autor für den Um- und Ausbau Bratislavas als Hauptstadt der Slowakischen Republik den konkurrierenden Einfluss des faschistischen Italien auf (S. 292). Neben diesen stärker stadtplanungs- und architekturgeschichtlichen Gesichtspunkten widmet sich die Studie am Beispiel von Prag und Reichenberg auch dem Einfluss der Reichsautobahnplanung für die Regulierung und Inszenierung des Stadtbildes.

Während Němecs Arbeit hier eine Vielzahl spannender Erkenntnisse und Archivfunde bietet, ist die Verortung der vorgestellten Umbauplanungen im „Referenzrahmen“ (S. 371) des Generalplan Ost nicht nur weniger vertieft, sondern auch eher kritisch zu bewerten. Unrichtig ist die Darstellung, die erste Version des Generalplan Ost sei im Auftrag des von Reinhard Heydrich geleiteten Reichssicherheitshauptamtes entstanden (S. 64). In der Forschung sind die unterschiedlichen Versionen und Planungshorizonte des Generalplan Ost, der nach der Besetzung Polens zunächst im Auftrag Heinrich Himmlers als „Reichskommissar für die Festigung deutschen Volkstums“ (RKF) für die Besiedlung der annektierten westpolnischen Gebiete ausgearbeitet wird, sowie der im Anschluss bis 1943 bearbeitete, aber nicht mehr abgeschlossene Generalsiedlungsplan notwendigerweise Gegenstand einer differenzierten Betrachtung. Němec spricht diesen Komplex sehr unterschiedlicher Gutachten etwas pauschal im Plural als „Generalsiedlungsplanungen“ an und konstatiert: „Die Generalsiedlungspläne können somit als der gemeinsame Nenner angesehen werden, auf den die Umgestaltung der jeweiligen Städte zu beziehen ist" (S. 67 sowie in ähnlichem Sinne S. 418). Das kann man entweder so lesen, als seien die behandelten städtebaulichen Umbauplanungen direkt von einer der Versionen des Generalplan Ost induziert, aber auch so, als seien die Neugestaltungsphantasien der Stadtplaner und die Germani- sierungspläne des RKF gleichgerichtete, aber voneinander unabhängige Phänomene. Da dies ein entscheidender Unterschied ist, wäre hier eine größere Klarheit zu wünschen. Eine direkte Abhängigkeit spezifischer Umbauplanungen von einer der Versionen des Generalplan Ost kann Němec an keiner Stelle nachweisen. Er konstatiert schlussendlich für die besetzten polnischen Gebiete: „Eine übergeordnete und von den Reichsstellen kontrollierte Planung kann nicht festgestellt werden, gingen doch letzten Endes die gescheiterten städtebaulichen Projekte auf jeweils einen einzigen Auftraggeber sowie einen Architekten zurück und waren keineswegs repräsentativ" (S. 410). Gleiches mag man für die untersuchten Städte auf dem Territorium der ehemaligen Tschechoslowakei unterstellen.

Eine verwandte Problematik lässt sich auch mit Bezug auf den titelgebenden Begriff der „Ökonomisierung des Raums" diskutieren. Němec versteht darunter einen auf wirtschaftlichen Prämissen basierenden Prozess, der Ressourcen ein- und freisetzt, um Planungsräume zu generieren (S. 43). Damit können ebenso planerische Effizienzkalküle angesprochen sein wie das persönliche Gewinnstreben von Gruppen und Akteuren (S. 464). Němecs Konzept von Ökonomisierung bleibt damit von einer Mehrdeutigkeit geprägt, die offenlässt, welche spezifischen privaten, völkischen, ideologischen, machtpolitischen oder wirtschaftlichen Rationalisierungs- und Modernisierungsgewinne die nationalsozialistischen Stadt- und Raumplaner jeweils von ihren Interventionen erwarteten. Vor den Vorzügen des neu erschlossenen Materials verblassen diese systematischen Bedenken allerdings schnell und man gewinnt den Eindruck, dass Němec in dem ohnehin schon voluminösen Werk nur einen Teil seiner umfassenden Quellenund Literaturkenntnisse darstellen kann. Im Abschlusskapitel, das der Kontextualisierung der Ergebnisse gewidmet ist, unterbricht er immer wieder seine Argumentation, um auf ergänzende Fallbeispiele, Quellen und wissenschaftliche Debatten hinzuweisen, die die Leserschaft neben der deutschen und angelsächsischen auch die tschechische, slowakische und polnische Literatur erschließen. Diese breite Übersicht macht seine Arbeit für Architektur- und Planungshistoriker/-innen zu einer außerordentlich wertvollen Lektüre.

\section{Vollständige bibliographische Angaben des rezensierten Werkes: \\ Němec, Richard (2020): Die Ökonomisierung des Raums. Planen und Bauen in Mittel- und Osteuropa unter den Nationalsozialisten 1938 bis 1945. Berlin: DOM Publis- hers. 496 Seiten. 480 Abbildungen.}

